\title{
Innovative Teaching and Capacity Building Approach: A Talent Management Prospective for Power Sector in Pakistan
}

\author{
Junaid Alam Memon ${ }^{1}$, Fateh Muhammad Mari ${ }^{2}$ \\ Faiz $\mathrm{Shah}^{3}$, Usman Mustafa ${ }^{4}$
}

\begin{abstract}
On job training serves as one of the prime tools of staff capacity development and talent management in any public or corporate entity including the power sector distribution companies (DISCOs) in Pakistan. This DISCOs used this approach to train more than 400 officials at Asian Institute of Technology, Thailand, hoping it to improve their performance in addressing Pakistan's power sector crisis. This paper evaluates this capacity-building intervention by gathering the perceptions of trainees and top management to understand the ways this multi-level, integrated capacity-building program enhanced the professional quality of customer services. The question that emerges in backdrop of such initiatives is whether this and other similar investments in human resource development (through effective, innovative and relevant teaching) can improve efficient services delivery. The paper presents a thematic analysis of qualitative and descriptive data collected from randomly selected participants and reviews their feedback on this question. The results suggest a thorough examination of the relationship between human development and organizational capacitybuilding with indicators of service quality in Pakistan's power sector.
\end{abstract}

Keywords: Innovative teaching, Training, Capacity Building; Transmission and Distribution Efficiency; Power Management

\footnotetext{
${ }^{1}$ Assistant Professor, Pakistan Institute of Development Economics

Email: memon@pide.org.pk

2 Planning and Development Department, Government of Sindh

Email: fateh.marri@gmail.com

${ }^{3}$ Head, Development Management, Asian Institute of Technology, Thailand

${ }^{4}$ Chief, Project Evaluation and Training, Pakistan Institute of Development Economics

Email: usman@pide.org.pk
} 


\section{Introduction}

Power distribution companies in Pakistan confront challenges in meeting the emerging and competing energy demands of households and industries. They have been frequently accused for poor management of Pakistan's power distribution. Among others, the governance and institutional capacity serve as the major reasons for power shortages (Alahad, 2012). The country suffers from inadequate capacity and human resources constraints, leading to energy waste and prolonged and frequent blackouts (Bacon, 2019; NEPRA, 2019). Common perception as well as scholarly conclusions suggest that these companies lack effective management and accountability mechanisms which results in corruption, revenue leakages and ultimately poor performance (Zameer \& Wang, 2018). Governance issues also manifest from high line losses, and poor cost recovery (Rafique \& Rehman, 2017). Besides, a suboptimal and expensive energy mix and new regulatory framework has made the energy generation, management and distribution even more complex (Kessides, 2013).

Realizing the importance of talent and institutional improvement, the power sector distribution companies (DISCOs) initiated a capacity building and staff development program at Asian Institute of Technology Thailand. An innovative teaching and training approach was adopted in the design and methodologies to improve the performance of these organizations. The approach that is termed as staff development and talent management in the literature, justified DISCOs investment in training their 500 officials.

The capacity building plan was termed as Energy Distribution Services Management and Technology (EDSMAT). The portfolio, comprising professional trainings, a master's degree, and executive trainings for managers and technical personnel of four DISCOs, was developed by Asian Institute of Technology (AIT) Thailand in response to specific training and development needs identified by the various DISCOs in a series of workshops in 2011 and afterword. The first component of EDSMAT portfolio, called Technical and Professional Training Program (TPTP) included seventeen (17) non-degree professional and technical courses covering four major strands (Table 1). About 436 nominees from four DISCOs, namely Hyderabad Electric Supply Company (HESCO), Islamabad Electric Supply Company (IESCO), Lahore Electric Supply Company (LESCO), and Multan Electric Power Company (MEPCO), participated in these training programs at the AIT campus in Bangkok, Thailand. The TPTP course faculty were drawn from AIT's School of Engineering \& Technology, School of Environment, Resources \& Development, and Asian Institute of Technology-Extension (AITE). Additional expertise was brought in 
from the relevant AIT academic and industry networks in Thailand, Australia and other countries.

Table 1

EDSMAT Phase-1 Courses

\begin{tabular}{ll}
\hline Major Strand & Name of Course \\
\hline Management & - Administration and Human Resource Management (HRM) \\
\& Human & - Health and Safety (HandS) \\
Resources & - Project Management (PrjM) \\
Management & - Construction Management (ConsM) \\
& - Materials and Procurement Management (MPM) \\
Customer & - Contract Management (ContM) \\
Orientation & - Commercial Management and Customer Services (CMCS) \\
Economics \& & - Financial and Economic Planning (FandEP) \\
Finances & - Analysis of Investment Projects (AIP) \\
& - Project Procurement (PrjP) \\
Technical & - Planning \& Design of Power Transmission \& Distribution \\
Trainings & System (PDPTD) \\
& - Environmental and Social Assessment and Management \\
& (ESAM) \\
& - Grid Station Operations Management (GOM) \\
& - Supervisory Control and Data Acquisition (SCADA) \\
& - Remote Metering System (RMS) \\
& - Geographic Information System (GIS) \\
& - Enterprise Resource Planning (ERP)
\end{tabular}

\subsection{Objectives of the Study}

With this backdrop, this paper reviews EDSMAT Phase-1 wherein hundreds of DISCOs officials were sent abroad for training. These trainings were arranged in a wide range of academic, technical and professional education programs, and returned to their parent organizations with new perspectives on power distribution and management. The paper assesses that how this innovative teaching and training at AIT built the officers' capacity and improved service delivery. The challenge of human resource development and organizational capacity-building remains in lockstep with the well-documented technical, structural and financial constraints that shape Pakistan's energy landscape. Thus, the role of human resources must be studied and understood for efficiency and effectiveness of service delivery. The paper also explores for this cohort if they found ways to bridge existing gaps in the operational and financial efficiency of 
their installations, or motivate peers and staff to overcome prevailing structural and nonstructural constraints?

\section{Literature Review}

Pakistan, often in the news for its chronic power shortages since 200405, was an electricity surplus country until the late 1990s. Afterwards, the electricity deficit stood between 5000-7000 MWs despite highly ambitious electoral promises and efforts. The half of the country's installed power generation capacity remains indolent (NEPRA, 2017; NTDC, 2016), necessitating up to 20 hours of load-shedding in the rural and 14 hours in the urban areas (Kugelman, 2015). The economic cost of load-shedding that was between 2.0 and 2.5 percent of GDP in 2008-2009 reached to 7.0 percent or Rs14 billion in 2015 (DAWN, 2016). Despite the government's expressed urgency to address it as a top priority, and the clearly defined adverse political and economic implications, the power crisis remains out of control. To Hussain et.al., (2016), Pakistan will continue to grapple with insufficient power supply all its productive economic sectors till 2020.

Amidst the sense of urgency, researchers from diverse disciplines have focused on various aspects of the power crisis and ways of tackling it. Hussain et.al., (2016) focused on forecasting general and sectoral electricity consumption. Mirza et al., (2014) and Raza et al., (2015) gauged the impact of electricity consumption and conservation policies on the country's economic growth and trade. Kugelman (2015), Kessides (2013), Alahad (2012) and Malik (2012) studied the Pakistani power sector's governance and institutional issues. Latest research focus on potential of renewable technologies in helping Pakistan solve its energy crisis (Kamran, 2018; Tahir \& Asim, 2018) and consumer coownership of renewable energy systems (Memon \& Hussain, n.d.).

A detailed literature review suggest that the primary cause of Pakistan's power crisis is rooted in the country' ageing and inefficient power generation and distribution infrastructure, and an increasing dependence on expensive imported fossil fuel at non-optimal tariffs (see also, Awan, Samad, \& Faraz, 2019; Walker, Canpolat, Khan, \& Kryeziu, 2016). It is also known that the problem is exacerbated by significant institutional and organizational weaknesses that have led to poor financial management, particularly circular debt, hold-over policies that institutionalize rent-seeking, and incompetence at all levels (Malik, 2012).

\subsection{Research Design}

\section{Research Methodology}

The study applied participatory evaluation for measuring the participants' reaction towards the training. It made use of five feedback loops 
(FBL) while approaching the study objectives (Figure 1). FBL-1 was the review of training documents and initial evaluations by the course participants upon the training completion; FBL-2 was the information gathered through an online questionnaire survey of the EDSMAT Phase-1 participants; FBL-3 was the information obtained from the individual presentation by some of the participants and Focus Group Discussions (FGDs); and, FBL-4 was individual interviews with major stakeholders. FBL-1 through FBL-4 facilitated the production of FBL-5 - the final outcome of the entire exercise that is supposed to inform all major stakeholders about future conduct of similar programs and writing this communication (Figure 1).

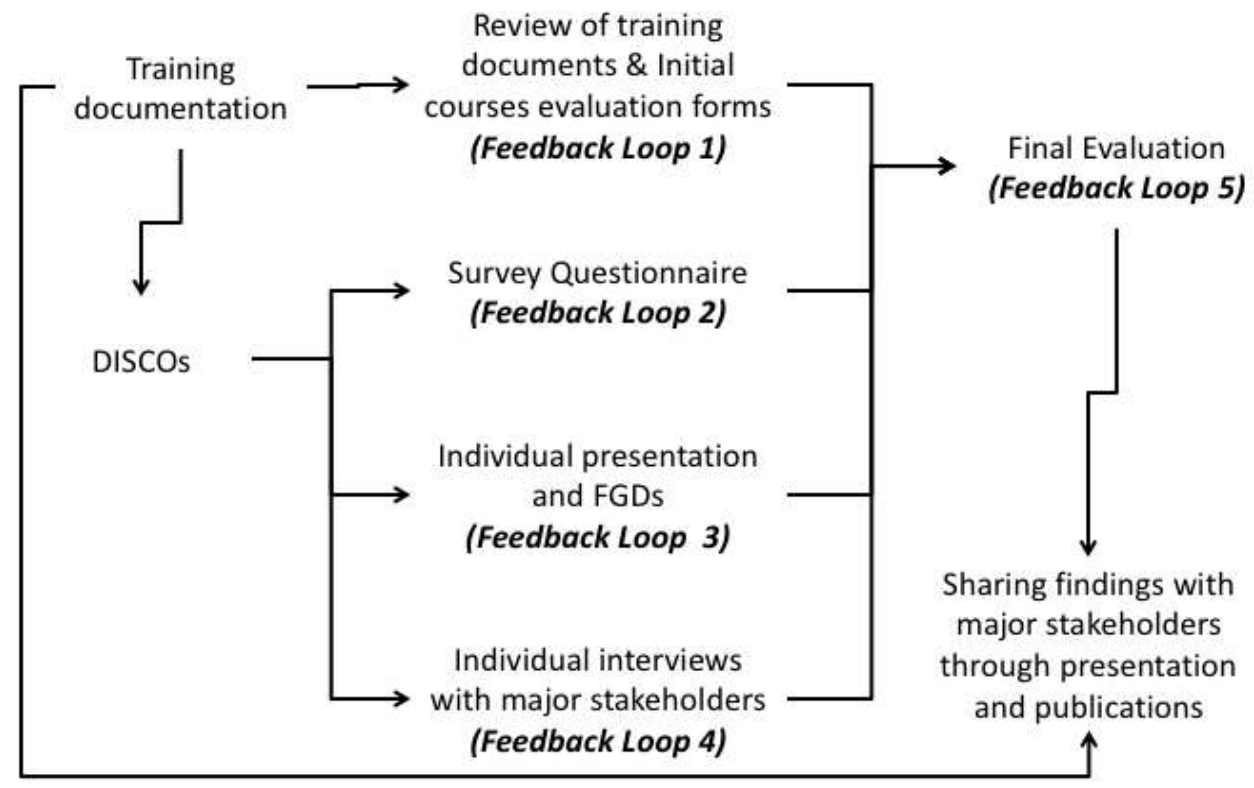

Figure 1: Research Design of the study

Although all FBLs were important in evaluating EDSMAT Phase-1 for achieving its stated objectives, some sources weighted more than the others. Specifically, the FBL-1 and 2 were just additional sources of available information that enhanced the understandings obtained through the FBL-3 and 4. This discrimination between data sources was intentional due to interest in the indepth understanding of participants' observations about the effectiveness of EDSMAT Phase-1. The key information under FBL-3 and FBL-4 came from four cohorts, namely, the participants, participants' immediate line supervisors, academic representatives of companies, EDSMAT coordinators at AITE. 


\subsection{Sources of Data}

\subsubsection{Review of training documents \& initial courses evaluations}

This was the first level of evaluation framework. AITE provided EDSMAT Phase-1 documentation, course materials, course evaluations and other helpful material such as the trainees' contact list. These documents' review served multiple purposes. Firstly, it helped understand the purpose and methodology of each course and EDSMAT training program. Secondly, the review of initial evaluations gave some idea about the logistic arrangements and on the spot views of course participants. Finally, it helped the questionnaire and checklists design to best feed FBL-3 and FBL-4.

\subsubsection{Survey Questionnaire}

The survey questionnaire generated another information layer to triangulate the insights obtained through individual presentations, FGD and stakeholder interviews - the so called data triangulation (See Denzin, 1970). The survey contained 20 questions comprising 7 profile questions and 13 specific questions as per TORs of the evaluation (Table 2). The question, asking the 'Name of respondent,' was optional for those who could hesitate to disclose their identity. Besides some general instructions, each question contained a separate set of instruction given in italics. Although the questions were mostly close ended, each contained an open space for comments and elaborations.

Table 2:

Conceptual Framework: specific questions investigated in the survey

Specific Questions

1. Were the topics of each training course relevant to the participants' needs and company initiatives?

2. Have the topics addressed gaps in the capacity building for officers and staff of the power companies?

3. Have the topics been organized in a logical sequence towards creating a holistic learning package?

4. Were the training methodologies appropriate for the level of knowledge and skills of participants?

5. Have the training methodologies enhanced the learning process and made concepts easier to grasp?

6. Have the training methodologies brought the knowledge and experience of participants?

7. Were resource persons appropriate for the topics they were chosen for?

8. Have the resource persons enhanced the training methodologies?

9. How were the training courses managed in terms of logistics and other 
preparations?

10. Have the participants improved on how to carry out their tasks in their respective offices?

11. Have there been any changes done in the way things are conducted in the participants' workplaces that may be attributed to the knowledge and skills gained in training programs?

12. How could future training programs be done better for the Phase-2 of EDSMAT?

13. Are the immediate outcomes of training as evidenced in participants' workplaces sustainable?

To make this layer of information somewhat unobtrusive, the research team designed an online survey questionnaire for the self-administration. It was distributed to the entire mailing list (population) obtained from AITE following the standard mail survey methodology (Bryman, 2016; Neuman, 2011). Researchers initially envisaged the survey participation as voluntary but with the $3^{\text {rd }}$ reminder sent after one month of the initial questionnaire distribution, still the response rate was mere 19 percent. So, strategy was changed by involving the DISCO heads. This raised the response rate to $43 \%$ percent (Table 3 )

Table 3

DISCO wise participation in online questionnaire survey and FGD

\begin{tabular}{lcc}
\hline DISCO Name & Participation in online survey & $\begin{array}{c}\text { Participation in FGDs } \\
\text { (Freq.) }\end{array}$ \\
\cline { 2 - 3 } HESCO & Freq. (\%) & 21 \\
IESCO & $23(12.0)$ & 19 \\
LESCO & $63(33.0)$ & 22 \\
MEPCO & $56(29.3)$ & 16 \\
Total & $49(25.7)$ & 78 \\
\hline
\end{tabular}

\subsubsection{Individual presentation and FGDs}

The researchers visited HESCO, LESCO, IIESCO and MEPCO headquarters to carry out one FGD per DISCO. Each DISCO selected participants for the workshop and FGD session (Table 3). Except HESCO, for which the workshop and FGD was organized in a hotel in Karachi, all workshops and FGDs took place in the respective DISCO's headquarters. At the start, participants were given presentation about the purpose of meeting. Following that, each participant delivered a three-minute presentation on the preset outline where they shared the kinds of new knowledge and skills (if any) obtained through training and applied in handling of DISCO affairs. Besides, they also shared the impact of the training on their motivation towards effective working of 
DISCOs. This followed FGDs where the discussion was open and interactive. There researchers' role was to raise issues of interest and guiding the discussion.

\subsubsection{Individual interviews with major stakeholders}

The researchers also conducted in-depth interviews with major stakeholders: the course participants, their immediate line supervisors, academic representatives of DISCOs, and AITE program coordinators. The entire theme of such interviews revolved around how learning was achieved and applied.

\section{Data Analysis \& Interpretation}

Qualitative data was thematically analyzed as per framework given in Table 2 in three subcategories namely: major argument, counter arguments, and synthesis of various aspect of interest under each question. Most of the quantitative data were acquired through five-point Likert Scale. This data were summarized using descriptive statistics including the weighted average index (WAI) suggested by Miah (1993).

\subsection{Participants View on Importance of Training and Satisfaction}

Participants rated training as highly important in terms of its relevance with their job and showed an overall satisfaction with its conduct. They also expressed that AIT used innovative methods of teaching and invited practitioners from relevant industry as trainers. This was reflected not only from FGDs and stakeholder meetings, but also from the results of online survey. Results suggest that average scores given to the importance of training were slightly higher than those given to satisfaction with training (Figure 2c). This implies that even those who were a bit skeptical about the conduct of training also perceived it as an important intervention. Despite this consensus, for a few participants, the training was 'just okay.' This was understandable as FGDs revealed that in some instances, the level of understanding and course relevance varied across participants.

\subsection{Contents of the Training}

It clearly came out of the FGDs that respondents' opinion on the overall importance of training was because of its relevance to their professional needs. This proposition is further supported by the results of online survey where the overwhelming majority viewed the relevance of training as high (Figure 2a). This variation in degrees of relevance to the course participant that online survey captured was because of the differences of their current job assignment with the training they received through EDSMAT. Essentially, this was because the course participants' selection by DISCOs that sometimes was sub-optimal which made the content irrelevant for some. Otherwise from interviews with the top management of DISCOs and AITE officials, it was found that AITE team 
finalized the course contents offered in EDSMAT Phase-1 after several consultations and meetings with DISCO representatives in Pakistan.
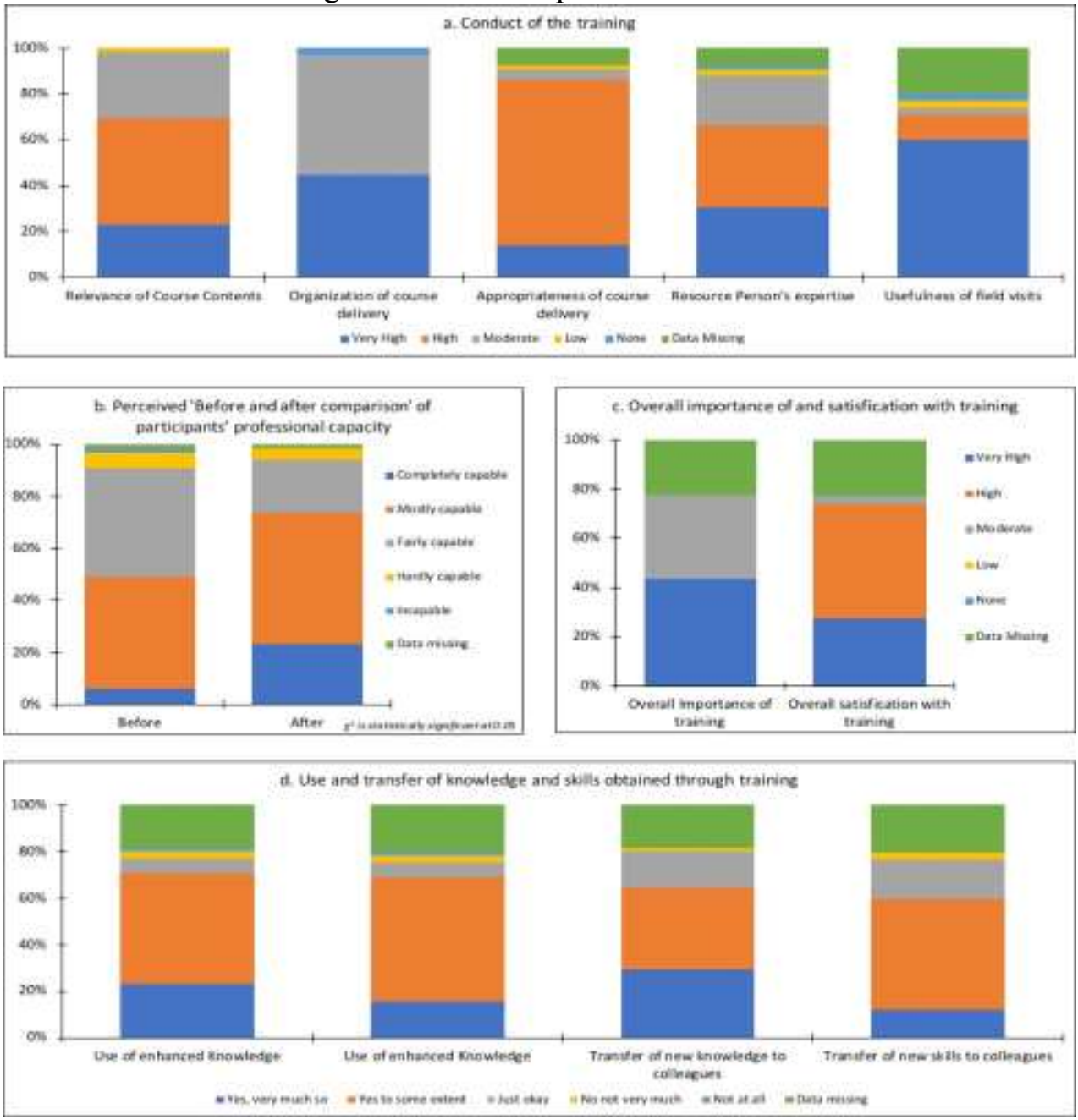

Figure 2: Evaluation of EDSMAT Phase-1

FGDs provided useful insights on the issue of course relevance and content appropriateness for the selected officials. There was a consensus that engineers cum power managers require hands-on knowledge of various issues ranging from different technical, financial, HRM aspects to customer relations to effectively manage power distribution task. Nevertheless, the depth of knowledge required by an engineer cum manger would certainly be different from those 
working in any support department - say finance. This essentially implies different treatment to those with prior professional knowledge of discipline and those who require just basic managerial understanding.

It is worth mentioning that even when the training could not introduce any new concepts, the participants reported to have gained a certain degree of conceptual refinement on the already known topics. Reportedly, in some cases, the training contents needed customization for their application in the Pakistani context within which the participants were supposed to serve. For example, the participants of Commercial Management and Customer Service Course opined that the contents were more reflective of the advanced countries thereby had no or very little relevance to the customer service in Pakistan.

\subsection{Training Conduct and Methodology}

FGDs participant acknowledged the AITE for its professionalism in the organization, the sequence and delivery of training courses and regarded it as a commendable experience. Even the participants, who were professional trainers in DISCO academies, shared this opinion. The results of the questionnaire survey further validated this view as the majority of the respondents categorized the training in the range of highly to fairly organized and sequential (Figure 2a). Despite promising reports from multiple data sources, the entire training did not go in an equally smooth manner across different courses. For example, in a couple of training courses, resource persons (RPs) were could not deliver effectively due to the lack of their English proficiency. The distorted communication and impeded the learning. These respondents were clearly reflecting on the deficiencies in training logistics and arrangements as emerged from the FGDs.

Besides, above-mentioned problems, FGD participants generally passed positive remarks about the RPs' subject grip and expertise. Most of the survey respondents reported that RPs usually introduced new concepts to them (Figure 2a). Nevertheless, many participants still opined that RPs could only occasionally introduce something new to them - as in most cases they were taught familiar concepts (Figure 2a). Despite that, one should appreciate the fact that the training participants were already professionals having practical insights on various aspects of the power distribution and management. Therefore, their opinions are understandable when they complain that RPs offered nothing new to them (Figure 2a). The FGDs participants opined that course delivery was effective in making difficult concepts easy to grasp. Overall results of the online survey were satisfactory on this aspect of training also (Figure 2a).

Despite, some hurdles in the learning due to communication in the third language, the training appeared to be reasonably interactive as many FGDs 
participants and online survey respondents expressed that they could frequently share their knowledge and experience in discussions and learning. Experiences shared by the FGDs revealed that some participants were quite vocal and expressive while others were a bit shy. This essentially implies that RPs were to be given explicit instruction in their TORs to provide special attention to the participant who appear to be quiet and shy.

According to FGD participants, the most tangible training outcome was exposure that the participants obtained through foreign visit and training. Most survey respondents also expressed similar views (Table 5). Field visits provided participants an opportunity to see how differential handling of everyday issues, common across DISCOs in different countries, could affect the efficiency and outcome. Essentially, they could find new and innovative ways of handling routine and old tasks and bring efficiency. In some cases, the concepts still vague during lecturing were clarified during the field visits when participants could see applications. What impressed many participants was to see the commitment of Thai professionals as well as short and simple decision-making processes in contrast to what they confront in Pakistan.

Despite everything good about the field visits, there were some problems. In one instance, the participants travelled hours to reach at a Thai DISCO where one of the executives gave them a presentation. However, the executive excused for not demonstrating the actual operations for which he/she was talking, and the participants were expecting. In another instance, despite knowing that the participants belong to the distribution side, the AITE arranged their field visit to a power generation facility. The relevant participants of FGDs considered such field visits of no utility in improving the efficiency on the distribution side.

\subsection{Training's impact on knowledge, Skills and Practices}

The training was particularly successful in sensitizing the participants about the emerging issues of sustainability such as environmental considerations. Participants highly regarded the awareness and knowledge of new concepts, which they were unfamiliar before participating in the training. For example, those engaged in the transmission and distribution of electric power, revealed that before the training they were hardly aware of the Environmental Impact Assessment (EPA). Similarly, those who participated in health and safety training found health as a particularly new concept earlier ignored despite its prime importance. Public Private Partnership (PPP) was another new area for power engineers narrowly trained on the technical aspects of electricity distribution and management.

In some cases, the participants were able to create linkages between the situation in Pakistan and the one demonstrated to them during course training. 
For example, those who attended the procurement course revealed that in Pakistan, the procurement responsibility resides usually few officials that leads to inefficiency and in some cases, corruption. However, they knew from the training that responsibility sharing could yield high performance and transparency. They could exactly point out the need of job description and thus could link it with their DISCOs HRM issues.

\subsection{Training's Success in bridging the Capacity Gap}

Besides broadening the employees' overall awareness and understanding of contemporary electric power management issues, the training should have bridged the gap in trainee's capacity to perform their official duties. For that, EDSMAT Phase-1 was substantially successful. Although opinion on the degree of success varied across survey respondents, the majority considered it successful for the most part. For about one fourth of the respondents, it was just okay. Only a few were unconvinced about the training's success (Figure 2b).

Questions asking the respondent to compare their capacity before and after the training were also included in the survey and FGD checklists. The survey results indicate that with varying degrees, the majority perceived themselves capable of performing their job effectively even before they participated in the training (Figure 2d). Nevertheless, each of the respondents perceived some degree of enhancement in their capacities after the training. None of them suggested indifference before and after participating in the training (Figure $2 b$ ).

\subsection{Application of Knowledge and Skills obtained through Training}

Like questionnaire survey respondents, the FGDs participants also revealed that they could not completely apply the new knowledge and skills obtained from the training (Figure 2d). In some cases, the participants could distinguish between the applicable and inapplicable parts of new knowledge and skills. For example, they could realize that given the costly investment required in building new infrastructure and poor governance, the remote metering in some of the DISCOs was difficult to apply for domestic consumers. However, the technology was readily applicable to the industrial clientele due to affordability and absence of problems like power theft. Similarly, those who learned about the environmental and social impact assessment could readily find its application in the transmission side but were indifferent on its application in the distribution side.

The FGDs unveiled various obstacles in new knowledge's application. The HRM course trainees found the application difficult in the public-sector where the political patronage restricts the induction of skilled people. In such situation, career planning and other skills had no immediate utility. In another cases, some 
parts of learning were not applicable in their companies because the missing infrastructure and support. For example, those participated in Management Information System (MIS) and GIS metering training highly regarded new knowledge, but they did not see its immediate utility. Nevertheless, considering the fast-rack technological changes, they were happy that they have advanced knowledge of innovations. In fact, after training, one of the DISCOs installed first remote meter with the help of Engro-Pakistan. Resultantly, they were enthusiastic for the day when they could extend this facility to all consumers and apply new knowledge and skills.

The FGDs participant highlighted several other issues that hindered the application of new knowledge and skills. Frequent transfer and postings also made new knowledge and skills redundant. Some pointed out towards the legal constraints in the application of new knowledge and skills, particularly of the new procurement methods such as the Special Case Method, Negotiation and Eprocurement due rigid procurement laws in Pakistan.

\subsection{Transfer new Knowledge and Skills to Colleagues in Company}

Despite somewhat optimistic results of online survey regarding the transfer of new knowledge and skills to colleagues (Figure 2d), the FGDs revealed that all attempts in this direction were informal. None of the DISCOs established any formal platform for the returnees where they could share their new knowledge, skills and experiences with their colleagues. Surprisingly, all the DISCOs were missing the opportunity of systematically multiplying the benefits of this costly investments.

\section{Discussion}

Conceptually, the everyday application EDSMAT Phase-learning among DISCOs hinged on three key actors: AITE, the participants and DISCOs, more so on the latter two. The AITE had been mostly successful in the knowledge provision through training in an innovative teaching and learning environment as DISCOs demanded. From training need assessment to courses design and delivery, it relied on participatory approach that brought higher satisfaction among the trainees and their supervisors. Even the participants who could not learn much from the lecturing, the exposure they obtained was brilliant as they could compare the technical and institutional contexts of Pakistani and Thai DISCOs when addressing similar problems. The participants often thought that training uplifted their morale, made them feel capable being catalysts in their DISCOs. Directing the participants towards attitude change was perhaps the most valued outcome of EDSMAT Phase-1. These findings are consistent with the 
theoretical and empirical insights provided by Lacerenza et.al. (2017) and Alias et. al. (2019).

Nevertheless, in some areas the AITE could pay more attention and further the program's success. First, it could be observed that the experiment of mixing participants with different needs, levels of understanding and prior knowledge in a single course was not much successful. Outcome of any individual course could increase manifolds if AITE had specified whether the course was basic or advanced besides suggesting that who could gain most from the course. Such specification could help the DISCOs select a homogenous group of participants having similar needs and level of understanding and prior knowledge. Findings of Gerpott et al. (2019) also suggest paying attention to the diversity among training participant and its management for maximizing training effectiveness.

Second, appreciation that English was the third language of communication between some of the resource persons and trainees could help AITE increase the over quality of course delivery. Third, the training could be more fruitful if AITE had clearly examined the design of each course for maintaining a healthy balance between lecturing and practical/field visits. Last, but not least, AITE could improve the field visit outcomes (and thereby of training) by ensuring that the selection of sites was purposeful and thematic, seek hosts' advance consent to demonstrate their operations, plants and premises; and putting-in-place necessary logistics (e.g., translators).

The DISCOs also did a commendable job in coordinating with AITE for the design and execution of EDSMAT Phase-1. The course portfolio Error! Reference source not found. clearly indicates the vision of the DISCOs' top management for the overall revamping of companies both on the operational and institutional fronts. The DISCOs could even rightly identify some of the courses such as the RMS that closely fits with the forthcoming technological developments in some of the DISCOs. Although the DISCOs arranged everything exceptionally well, certain aspects if handled carefully could bring a major difference in the outcomes of training.

Despite generally selecting highly vibrant and enthused course participants, sometimes the selection was not optimal particularly in instances where the selected officials' currents assignment was different from their training courses. Thus, they could not readily apply new knowledge in their everyday workings and increase the efficiency of their company. Appropriate emphasis on selecting the right person for the right course could substantially enhance the training outcomes. These factors are also highlighted in Kodwani (2017) in 
appreciating the role of employer organizations in getting most out of their investment in training.

Moreover, an important opportunity, that still exist but remains underutilized among all DISCOs, was the systematic multiplication and sharing of new knowledge and skills obtained through training. The sharing of new knowledge, skills and even course documentation was mostly random and informal, as the participants were not officially compelled to do it on any forum. Studies in other industries in Pakistan, e.g., Rafique et.al (2018), also suggest that a system encouraging the knowledge sharing by those trained to those on yet to be trained is the most cost-effective way multiply the returns on training investment and improve organizational performance. As suggested by Brooke (2017) as well, there could be various innovative ways to institutionalize the systematic sharing and multiplication of knowledge and skills, which could further the training outcomes.

\section{Conclusions}

Training effectives can be conceptualized as a function of trainer or training institution, those being training and the employer who send their employees for training. The latter two actors may help the trainer or training institution to understanding their aspirations from their training participation to give best value for money. However, understanding that the trainer may be more experienced than those seeking the training, a professional approach to training design, delivery, logistics, and diversity management is pre-requisite for successful training. While training ideally needs to bring new knowledge, the feasibility of near future application of the ideas and technologies exposed to participants during the training also need consideration. Nevertheless, no matter how well a training is imparted, the application in workplace may face challenges emerging from training and job mismatch, and, the contextual differences in what is taught and the extent it can be applied in workplaces and rigid bureaucracies. Finally, training knowledge multiplication through formal sharing is a lowhanging fruit that can be reaped with slight investments in institutionalizing the formal sharing of new knowledge with collogues who did not get the training opportunity.

\section{References}

Alahad, Z. (2012). Pakistan 's Energy Sector: From Crisis to Crisis - Breaking the Chain. (PIDE Monograph Series). Islamabad, Pakistan: Pakistan Institute of Development Economics. Retrieved from http://www.pide.org.pk 
Alias, S. A., Hanafi, M., Ong, A., Rahman, A., \& Rahim, A. (2019). The Role of Training Design Factors in Influencing Training Effectiveness among Public Service Employees. International Journal of Academic Research in Business and Social Sciences, 9(5), 898-913.doi.org/10.6007/IJARBSS/v9i5/6016

Awan, H. S., Samad, G., \& Faraz, N. (2019). Welfare Analysis of Electricity Subsidies in Pakistan. In PIDE Working Papers (164) (p. 22). Islamabad, Pakistan: Pakistan Institute of Development Economics.

Bacon, R. (2019). Learning from Power Sector Reform: The Case of Pakistan. Policy Research Working Paper (8842). The World Bank Group (Energy and Extractives Global Practice). Retrieved from http://www.worldbank.org/prwp.

Brooke, J., Mohd Rasdi, R., \& Abu Samah, B. (2017). Modelling knowledge sharing behaviour using self-efficacy as a mediator. European Journal of Training and Development, 41(2), 144-159.doi.org/10.1108/EJTD-042016-0021

Bryman, A. (2016). Social research methods. Oxford university press.

DAWN. (2016). 7 facts about Pakistan's energy crisis - and how you can help end it. Retrieved February 25, 2017, from https://www.dawn.com/news/1275116

Denzin, N. K. (1970). The research act in sociology: A theoretical introduction to sociological methods. London: Butterworths.

Gerpott, F. H., Lehmann-Willenbrock, N., Wenzel, R., \& Voelpel, S. C. (2019). Age diversity and learning outcomes in organizational training groups: the role of knowledge sharing and psychological safety. The International Journal of Human Resource Management, 1-28. https://doi.org/10.1080/09585192.2019.1640763

Hussain, A., Rahman, M., \& Memon, J. A. (2016). Forecasting electricity consumption in Pakistan: The way forward. Energy Policy, 90. doi.org/10.1016/j.enpol.2015.11.028 
Kamran, M. (2018). Current status and future success of renewable energy in Pakistan. Renewable and Sustainable Energy Reviews, 82(November 2016), 609-617. doi.org/10.1016/j.rser.2017.09.049

Kessides, I. N. (2013). Chaos in power: Pakistan's electricity crisis. Energy Policy, 55, 271-285. doi.org/10.1016/j.enpol.2012.12.005

Kodwani, A. D. (2017). Decoding training effectiveness: the role of organisational factors. Journal of Workplace Learning, 29(3), 200-216. doi.org/10.1108/JWL-05-2016-0038

Kugelman, M. (2015). Pakistan's Interminable Energy Crisis: Is There Any Way Out? Washington, D.C.: Woodrow Wilson International Center for Scholars.

Lacerenza, C. N., Reyes, D. L., Marlow, S. L., Joseph, D. L., \& Salas, E. (2017). training design, delivery, and implementation: A meta-analysis. Journal of Applied Psychology, 102(12), 1686-1718. doi.org/10.1037/ap10000241

Malik, A. (2012). Power Crisis in Pakistan: A Crisis in Governance? Pakistan Institute of Development Economics Monograph Series. Islamabad, Pakistan.

Mehmood Mirza, F., Bergland, O., \& Afzal, N. (2014). Electricity conservation policies and sectorial output in Pakistan: An empirical analysis. Energy Policy, 73, 757-766. doi.org/10.1016/j.enpol.2014.06.016

Memon, J. A., \& Hussain, A. (n.d.). Country Chapter Pakistan. In J. Lowitzsch (Ed.), Energy Transition: Financing Consumer Ownership in Renewables. Palgrave Macmillan.

Miah, A. (1993). Applied statistics: a course handbook for human settlements planning, division of human settlements development. Bangkok, Thailand: Asian Institute of Technology.

NEPRA. (2017). State of industry Report 2016. Islamabad Pakistan.

NEPRA. (2019). State of Industry Report 2018. Islamabad, Pakistan: National Electric Power Regulatory Authority Islamic Republic of Pakistan. 
Neuman, L. W. (2011). Social Research Methods: Qualitative and Quantitative Approaches, 6th Edition. University of Wisconsin (Pearson).

NTDC. (2016). Power System Statistics 2015-2016. National Transmission and Dispatch Company.

Rafique, M., Hameed, S., \& Agha, M. H. (2018). Impact of knowledge sharing, learning adaptability and organizational commitment on absorptive capacity in pharmaceutical firms based in Pakistan. Journal of Knowledge Management, 22(1), 44-56. doi.org/10.1108/JKM-04-2017-0132

Rafique, M. M., \& Rehman, S. (2017). National energy scenario of Pakistan Current status, future alternatives, and institutional infrastructure: An overview. Renewable and Sustainable Energy Reviews, 69(October), 156167. doi.org/10.1016/j.rser.2016.11.057

Raza, S. A., Shahbaz, M., \& Nguyen, D. K. (2015). Energy conservation policies, growth and trade performance: Evidence of feedback hypothesis in Pakistan. Energy Policy, 80, 1-10. doi.org/10.1016/j.enpol.2015.01.011

Tahir, Z. R., \& Asim, M. (2018). Surface measured solar radiation data and solar energy resource assessment of Pakistan: A review. Renewable and Sustainable Energy Reviews, 81(May), 2839-2861. doi.org/10.1016/j.rser.2017.06.090

Walker, T. F., Canpolat, E., Khan, F. K., \& Kryeziu, A. (2016). Residential Electricity Subsidies in Pakistan: Targeting, Welfare Impacts, and Options for Reform (No. Policy Research Working Paper 7912). World Bank Group - Social Protection and Labor Global Practice Group.

Zameer, H., \& Wang, Y. (2018). Energy production system optimization: Evidence from Pakistan. Renewable and Sustainable Energy Reviews, 82(March 2016). doi.org/10.1016/j.rser.2017.09.089 
International Journal of Innovation in Teaching and Learning (IJITL)

Volume VI- Issue I (June 2020)

\section{Citation of this Article:}

Memon, J. A., Mari, F. M., Shah, F., \& Mustafa, U. (2020).Innovative Teaching Approach for Capacity Building: A Talent Management Prospective for Power Sector in Pakistan. International Journal of Innovation in Teaching and Learning (IJITL), 6(1), 51-68. 